Der glänzende Erfolg von Akehursts Studienbuch beruhte auch auf seiner Klarheit, Übersichtlichkeit und Eingängigkeit. Sie bleibt gewahrt trotz nunmehr größerer Detailfreude und Nachweisdichte. Wenn (sicher schon bald) künftig weitere Auflagen anstehen, wird Malanczuk gewiß darauf achten, daß beide Anliegen einander nicht beeinträchtigen.

Philip Kunig

\title{
Ignaz Seidl-Hohenveldern
}

\section{Völkerrecht}

9. neubearbeitete Auflage

Carl Heymanns Verlag, Köln, 1997, XXVI, 422 S., DM 68,--

Nunmehr liegt bereits die neunte Auflage des "Völkerrecht" von Seidl-Hohenveldern vor, in der die neuesten Entwicklungen der Rechtsprechung und internationalen Praxis eingearbeitet sind. Der Autor steht dem Einschreiten des Sicherheitsrats in Haiti und Somalia kritisch gegenüber; hier würden Schritte in Richtung einer Weltregierung unternommen, die die Souveränität einzelner - nach politischen Kriterien ausgewählter - Staaten beiseite schiebe. Zudem seien die beschlossenen Maßnahmen in Somalia wenig geeignet gewesen. Andererseits wird dem Sicherheitsrat ein weiter Beurteilungsspielraum zugestanden, der es zur Erreichung des obersten Ziels, der Friedenssicherung, auch erlaube, sich über manche rechtliche Bedenken hinwegzusetzen. In Ruanda wie in Bosnien-Herzegowina habe sich das Fehlen eigener Truppen der UNO negativ bemerkbar gemacht, in letzterem Fall habe es weiterhin an einem eindeutigen Mandat und einfachen Befehlsstrukturen gefehlt.

Trotz seines schon beachtlichen Umfangs gehört das Lehrbuch zu den kürzeren seiner Gattung. Es hat den Vorteil, noch ganz von vorn bis hinten gelesen werden zu können auch von Studenten. Andererseits müssen angesichts der Stoffülle irgendwo Abstriche gemacht werden. Seidl-Hohenveldern geht hier nicht den Weg der Beschränkung auf die wichtigsten Materien, wie es manche andere Autoren tun. Vielmehr stellt er das Fach in seiner ganzen Breite vor einschließlich der Internationalen Organisationen, sogar die Europäische Union wird einbezogen. Weiterhin wird die nationale Rechtsprechung zu völkerrechtlichen Fragen berücksichtigt und nicht selten kritisiert - so etwa die Entscheidung des Bundesverfassungsgerichts über den Fortbestand der einst unter sowjetischer Besatzungsmacht vollzogenen Bodenreform.

Diese gewaltige Materialmenge läßt sich dann freilich nicht umfassend erörtern. Die eigene Auffassung wird meist nur mit wenigen Strichen begründet, Einzelnachweise von Literatur und gegenläufigen Meinungen fehlen. Wer den Dingen auf den Grund gehen will, muß also andernorts weiterlesen; die vielen aufgeführten Beispiele machen Appetit darauf.

Ulrich Fastenrath 